ELORE (ISSN 1456-3010), vol. 19 - 1/2012.

Julkaisija: Suomen Kansantietouden Tutkijain Seura ry.

[http://www.elore.fi/arkisto/1_12/lukin_lec.pdf]

Ajankohtaista

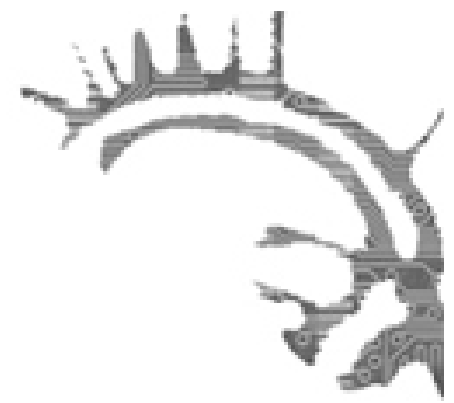

\title{
MUISTELTUJEN JA KERROTTUJEN MAISEMIEN KERROKSET
}

Karina Lukin

Lectio praecursoria Helsingin yliopistossa 10.12.2011.

Vuonna 1910 nuori Novaja Zemljan saarilta kotoisin oleva nenetsimies Tyko Vylka matkasi vuodeksi Moskovaan opiskelemaan luonnontieteitä ja maalausta. Lukuisat venäläiset tutkimusmatkailijat, joiden oppaana Vylka oli toiminut, pitivät häntä poikkeuksellisen lahjakkaana taiteilijana. Tämän lisäksi Vylkan Novaja Zemljaan liittyvää tietoutta pidettiin erityisenä. Venäläisen tutkimusmatkailija Aleksandr Rusanovin mukaan Tyko Vylka "luki luonnon kirjaa niin kuin me luemme kirjoja ja lehtiä" ja "oli Novaja Zemljan elävä kartta." (Perepletšikov 1917, 1.)

Vylka oli elänyt koko elämänsä Novaja Zemljalla metsästäjänä, kalastajana ja poronhoitajana. Elinkeinot loivat perustan liikkuvalle elämäntavalle, jonka pohjalta paikkojen ja maisemien tuntemus oli syntynyt. Neuvostoaikoina Vylkasta tuli Novaja Zemljan saarineuvoston pitkäaikainen puheenjohtaja. Hän jatkoi maantieteellisiä harrastuksiaan toimimalla Arkangelin alueeseen keskittyvän maantieteellisen seuran kirjeenvaihtajajäsenenä ja maalaamalla saariston paikkoja ja maisemia. Kun novajazemljalaiset 1950-luvulla pakkoasutettiin mantereelle ydinkokeiden tieltä, Vylka asettui Arkangeliin ja jatkoi kotiseutujensa kuvaamista.

Vylkan maalaukset asetetaan usein vastakkain venäläisten taiteilijoiden pohjoisen kuvien kanssa. Venäläisten maisemissa pohjoinen luonto on karu ja ankara, se on jään ja yön hallitsema maisema, tai epävieraanvarainen ja pelottava mutta myös selittämätön ja jännittävä paikka. Näille vastakohtaisella tavalla Vylkan maalausten on sanottu kuvaavan pohjoista luontoa arkisena ja kotoisena, vieraanvaraisena maisemana.

Maalausten väliset erot eivät kerro oikeasta ja väärästä tavasta kohdata pohjoinen ympäristö, mutta ne kertovat kahdesta hyvin erilaisesta tavasta. Erot tähdentävät, että 


\section{Karina Lukin: Muisteltujen ja kerrottujen maisemien kerrokset}

arkikokemuksen tasolla itsestään selvinä ja annettuina pidetyt paikat ja maisemat ovat paitsi konkreettisia, fyysisiä ja aistittavia, myös käsitteellistettyjä, kulttuurisidonnaisia kokemuksia ja osa yhteisöllistä tajuntaa.

Vylkan työt tarjoavatkin mahdollisuuden päästä lähelle nenetsien maiseman hahmottamisen ja käsitteellistämisen tapoja. Nenetsien paikan tajuun ja maisemakäsityksiin johdattavat myös paikannimet, suullinen perinne ja muistelu - puhe paikoista sekä paikoissa oleminen nenetsien kanssa. Juuri näitä suullisia ja kokemuksellisia aineistoja on käytetty nyt tarkastelussa olevassa tutkimuksessa, joka keskittyy Novaja Zemljan länsipuolella sijaitsevaan Kolgujevin saareen. Tutkimus kertoo nenetsien muistelemasta, kertomasta ja kokemasta Kolgujevin saaresta ja sen suhteista muihin nenetsien elinpiirissä oleviin paikkoihin.

\section{MuUtos}

Tutkimieni nenetsien parissa paikka ja maisema ovat polttavia aiheita, koska heidät on neuvostovuosina asutettu tundralta asutuskeskukseen. He ovat luopuneet liikkuvasta elämäntavasta ja asettuneet taloihin, koska näin uskottiin olevan parempi. He ovat poistuneet kotiseuduiltaan ja - samoin kuin Tyko Vylka ja monet muut nenetsit - he jatkavat tundran muistelemista ja kuvaamista visuaalisesti ja verbaalisesti.

Muutos on ollut nopea ja siihen on liittynyt voimakas ideologinen paine: liikkuvaa elämäntapaa pidettiin jälkeenjääneenä ja paimentolaisuutta tehottomana elinkeinona; kodasta haluttiin päästä asumismuotona eroon, koska se oli modernin, hyvän elämäntavan tiellä. Asutuskeskuksissa jokaisella nenetsillä oli mahdollisuus osallistua neuvostoyhteisön rakentamiseen ja sivistyneeseen elämään.

Moni nenetsi on kokenut elämän ilman tundraa tyhjäksi. Kun neuvostokoneisto rakensi kuvaa asutuskeskusten edistyksestä ja iloisesta elämästä, jonka taustalla entinen oli ankeaa raatamista, nenetsien puheessa oli päinvastoin. Tundralla oli rauha, siellä oli vapaus ja onni. Arjessa tundra ja asutuskeskukset elivät kuitenkin tundran mainetta nakertavassa yhteiselossa: tundra tuotti ruokaa, mutta työskentely siellä koettiin raskaaksi. Asutuskeskuksissa oli fyysisesti helpompaa, ja asutuskeskukseen alkoi rakentua neuvostoyhteisö, joka haki oikeutuksensa modernin yhteiskunnan saavutuksista.

Kenttätöideni aikana 2000-luvun alussa tundra oli edelleen keskeinen elämän ja elinkeinojen, mutta myös entisyyden maisema. Kolgujevin ainoan asutuskeskuksen, Bugrinon, asukkaille tundra edusti metsästykselle ja kalastukselle otollisia maisemia, joilla vierailtiin lähinnä kesällä. Myös muistelut ja kerronta sijoittuivat tundralle.

Nykyään tundra on polttava aihe myös sen takia, että Venäjän taloudelle keskeinen öljy- ja kaasuteollisuus keskittyy muun muassa nenetsien asuttamille tundrille. Maankäytöstä ja etenkin maankäytöstä öljy- ja kaasuteollisuuden jälkeen keskustellaan kiivaasti ja paljon, sillä Kolgujevin nenetsit eivät halua kokea Novaja Zemljan nenetsien kohtaloa. He haluavat jäädä kotiseuduilleen. 


\section{Karina Lukin: Muisteltujen ja kerrottujen maisemien kerrokset}

\section{Painolasteja}

Nenetsien kuvattiin elävän elinkeinojensa ja kulttuurinsa suhteen ahdingossa jo toista sataa vuotta sitten, 1840-luvulla, kun Matias Aleksanteri Castrén vieraili nenetsien asuttamilla seuduilla. Ajalle tyypillisessä kuvastossa nenetsejä ja muita pohjoisen alkuperäiskansoja uhkasivat venäläistyminen, venäläisten ja komien aiheuttama köyhtyminen, alkoholismi ja kulkutaudit. Näiden pelättiin yhdessä johtavan kielten ja kulttuurien kuolemaan. Useat Castrénin aikaiset uhkakuvat ovat tänään toteutuneet: nenetsit ovat omaksuneet venäjän kielen ja monet ovat hyljänneet äidinkielensä; perinteet ovat unohtuneet tai ne on haluten unohdettu.

Nenetsit ovat silti edelleen nenetsejä, minkä toteamiseen Castrénin ja hänen perintönään syntyneen tutkimuslinjan tuottamat materiaalit ovat tarjonneet perustan. Tämän fennougristiseksi nimettävissä olevan tradition lisäksi nojaudun tutkimuksessa folkloristiseen tutkimusperinteeseen.

Molempien tutkimusperinteiden painolasti on raskas. Molemmat tutkimusperinteet edustavat suomalaista huippututkimusta ja oman alansa kansainvälistä kärkeä. Ne ovat luontaisesti monitieteisiä tutkimus- ja opetuskokonaisuuksia, joiden arvo perustuu pitkien kenttätyöperinteiden ja laadukkaan arkistotyön tuottamaan tutkimuskenttään ja -otteeseen. Niillä on myös runsaasti yhteistä historiaa ja nykypäivää.

Niin fennougristiikan kuin folkloristiikankin ytimessä on halu ymmärtää ja arvostaa toisia kulttuureja, tutkijan omaa kulttuuria ja lopulta ihmisyyden monimuotoisuutta. Tällainen tutkimus on paitsi painoarvoltaan raskasta, myös hidasta. Inhimillinen monimuotoisuus ei ole ainoastaan tässä päivässä, vaan myös menneisyydessä, josta käsin muutokset ja jatkuvuudet hahmottuvat. Ainoastaan menneisyydestä käsin voimme osoittaa, että tänään ideologisesti sekä Venäjällä että Suomessa käytetty yhtenäisyys on moninaisuudesta muovailtu, hauras kuva.

\section{PÄÄLLEKKÄISET PAIKAT}

Nenetsien paikantajun ja maisemien tutkimus monipuolistaa yhtenäisestä Venäjästä luotua kuvaa. Arjen tasolla Venäjä koostuu pienyhteisöjen, kielten ja kulttuurien vuorovaikutuksessa - niin sanotusta Moskovasta huolimatta ja piittaamatta. Paikkojen ja maisemien ihmistieteellinen tutkimus perustuu käsitykseen siitä, että maisemaa ei voi lukea ainoastaan Rusanovin kuvaamalla tavalla luonnon kirjana, vaan myös kulttuurin ja yhteisön itseymmärryksen teoksena. Tutkimuksissa on tapana korostaa, että niin paikkoihin kuin maisemiinkin liitettävät moninaiset merkitykset ovat vaihtoehtoisia, päällekkäisiä tai limittäisiä ja vuorovaikutuksessa tai ristiriidassa keskenään.

Paikat ja maisemat eivät ole limittäisiä ainoastaan niiden yhteisö- tai kulttuurisidonnaisuutensa vuoksi. Ne ovat myös historiallisesti kerrostuneita. Maisemasta on mahdollista lukea luonnon muutosten, mutta myös ihmisten ja yhteisöjen toiminnan jälkiä, joita taas voidaan määrittää eri aikakausille. Yksilön tai yhteisön näkökulmasta paikkoihin ja maisemiin liittyy myös kokemuksia ja näin ollen muistoja, jotka voivat 


\section{Karina Lukin: Muisteltujen ja kerrottujen maisemien kerrokset}

kulkeutua yli sukupolvien. Ajan kerrokset peittävät toisia alleen.

Esimerkiksi Bugrinon asutuskeskus, jossa olen tehnyt pääosan kenttätöistäni, oli vielä 1800-luvun lopulla pieni kauppapaikka, jossa sijaitsi muutama säilytysaitta, venäläisten kauppiaiden rakennuttama ortodoksinen Käsittätehdyn ikonin nimeen pyhitetty kirkko ja papin ja diakonin asuintalo. Tätä ennen Bugrinon edustan rannikko on ollut merkittävää kalastus- ja merinisäkäspyynnin seutua. Sen merkitys kauppapaikkana oli ennen neuvostoaikoja toisarvoinen Kolgujevin kaakkoisrannikon Sharokin satamaan verrattuna ja nenetsien ortodoksisten rituaalien kannalta Sharokissa sijainnut kappeli tuntuu myös olleen tärkeämpi.

Uuden neuvostotalouden kauppa-asema ja hallinto päätettiin kuitenkin sijoittaa Bugrinoon. Neuvostokeskus oli pitkään venäläisten ja ukrainalaisten viranomaisten paikka, jonne nenetsit saapuivat ainoastaan tarvittaessa. Niin oli ollut tsaarinvallan aikanakin. Tsaarinaikaiset rakennukset purettiin pian ja tilalle alettiin rakentaa kollektiivitalouden tiloja, varastoja, kauppaa ja virkamiesten asuintaloja. Kirkosta tehtiin leipomo - myöhemmin se paloi.

2000-luvun nenetsit muistelevat asutuskeskuksen rakentamisen ja rakentumisen aikoja lämmöllä. Kirkkoa ja sen rituaaleja muistellaan neuvostoaikaisiin puhetapoihin tukeutuen irrationaalisina ja epähygieenisinä. Kokonaisuudessaan Bugrinon kirkkoa muistellaan vähän - se on jäänyt asutuskeskuksen alle. Bugrinon auvoista neuvostoyhteisöä ja yhteiskuntaa koskevassa muistelussa heijastuvat ne monet paremman elämän lupaukset, jotka jättivät alleen tsaarinaikaisen epätasa-arvon. 2000-luvun toiminnassa ja puheessa näiden lupausten nähdään rauenneen tyhjiin. Tämän päivän Bugrinoon liitetty kielteinen paikantaju on kielteinen juuri siksi, että neuvostokoneiston valoisassa tulevaisuudessa asutuskeskusten paikantajun kaavailtiin olevan hyvinkin paljon myönteisempi. Neuvostoaikainen tai nykyinen Bugrino eivät ole siis täysin peittäneet mennyttä, vaan menneisyyksien, nykyhetken ja tulevaisuuden näkymien välillä on vuoropuhelua.

\section{LIMITTÄISET PAIKAT}

Paikantajut ja maisemat eivät ole kerroksellisia ainoastaan ajan suhteen tai koska eri kulttuureja edustavat ihmiset kokevat maisemat eri tavoin. Niin muisti ja muistelupuhe kuin kerrontakin tai suullinen kansanperinne ylipäätänsä ovat määritelmältään kerrostunutta puhetta. Ne ovat hetkessä kerrottuja ja muotoiltuja ilmaisuja, jotka palaavat menneisiin kertomisiin tai tapahtumiin. Ne ovat kerrostuneita niin tutkijalle kuin kertojillekin. Muistelu ja kerronta sekä lisäävät maisemiin ja paikkoihin omia kerroksellisia kerroksiaan että käyttävät paikkojen muotoja ja tajuja hyväkseen. Niin muistelussa kuin suullisessa perinteessäkin välittyy sisältöjen lisäksi kerronnan tapoja ja keinoja ja lopulta kokonainen perinne. Tämä on viimeaikaisissa folkloristisissa tutkimuksissa ymmärretty lajien, sisältöjen, keinojen ja mahdollisuuksien järjestelmänä.

Toisin kuin yleisissä mielikuvissa saattaa olla, perinnettä järjestelmänä luonnehtii ennen kaikkea joustavuus, joka tutkimuksessani tulee esiin ennen kaikkea kertojien 


\section{Karina Lukin: Muisteltujen ja kerrottujen maisemien kerrokset}

taitona leikkiä ja taiteilla lajien, sisältöjen ja keinojen rajoilla ja niiden suhteilla. Tällaisen taiteen välityksellä hahmottuu Kolgujev, jonka ymmärtämiseksi on yritettävä katsoa saarta muualtakin kuin Bugrinosta käsin - vaikkakin sen läpi. Tämä asutuskeskuksessa minulle kerrottu saari on uskomustarinoiden ja myyttien, yliluonnollisten olentojen, ensimmäisten nenetsien ja muinaisten šamaanien maisema.

Nykyaikaan sijoittuvassa kokemuskerronnassa kolgujevilaiset kertojat liikkuvat uskomuskertomusten ja tarinoiden maailmoissa ja sijoittavat ne tämän päivän Kolgujeville. Niissä yksin tundralla liikkuvat ihmiset kohtaavat yliluonnollisen olennon tai joutuvat muutoin vuorovaikutukseen tuonpuoleisen kanssa täysin yllättäen ja tahtomattaan. Näissä kertomuksissa taiteillaan uskottavuuden rajoilla ja leikitellään uskon kanssa. Niissä hyödynnetään topografiaa eli paikkojen pinnanmuotoja, sillä yliluonnollisten olentojen ajatellaan yleisesti asuvan kodanmuotoisissa mäissä. Samalla kerronnassa synnytetään kansanuskon paikantajua. Näiden kertomusten avulla myös luodaan Kolgujevin maisemaan tuonpuoleinen peiliyhteisö, maan alla asuvat sjirtjat, joille saarelaiset ovat sekä vastakkaisia että rinnakkaisia.

Myyttisiin lajeihin viittaavissa muisteluissa luodaan maisemaan yhteisö, johon kolgujevilaiset ovat ennen kaikkea rinnakkaisessa suhteessa. Tässä puheessa viitataan nenetsien sankariepiikan piirteisiin ja motiiveihin ja leikitään myytin ja historian rajapinnoilla. Myyttien rakennetta hyödyntävissä kertomuksissa yhdestä eloon jääneestä perheestä kasvaa saaren vanhin sukulinja, joka kantaa mukanaan myös eteviä ja voimakkaita šamaanien apuhenkiä. Tämä sukulinja on olemassa edelleen. Se on yksi saaren muinaisista suvuista, jolla on oma elinalueensa eli sukumaansa Kolgujevin saarella.

Sukumaita muistellaan erityisellä latauksella. Maiden perustelut palaavat myyttisiin puheen lajeihin ja tapoihin ja niiden merkitys tänään on edelleen voimakas, vaikka sukumaat selvästi ovat entisen elämän maisemia. Muisteluissa ja myyttiseen menneisyyteen kiinnittyvässä puheessa keskitytään sellaisiin paikkojen merkityksiin, jotka liittyvät tämän päivän saarelaisten itseymmärrykseen, siihen kuka kukin on. Se sijoittaa maisemaan yhteisön perustan ja lähtökohdan sille sukupolvien ketjulle, jota voi hahmottaa muisteluiden perusteella.

Sekä muisteluissa että kertomusperinteessä toistuvat šamaanien haudat kiinnittyvät entisiin sukumaihin, sillä kunkin šamaanin hauta sijaitsee hänen sukumaillaan. Šamaanien haudat linkittyvät myös muisteluiden paikkoihin, esimerkiksi Sharokin satamaan tai yksittäisiin kotakyliin ja eri aikoihin riippuen siitä, milloin šamaani on elänyt ja kuollut, missä šamaani on muutoin toiminut ja millaisia merkkejä hänestä on jäänyt maisemaan. Šamaanien hautoihin liittyvä kerronta liikkuu jatkuvasti yhtäältä shamanistisen perinteen ja myyttien, toisaalta uskomusperinteen ja juoruilun rajamaastoissa. Se sijoittaa šamaanit omaan historialliseen aikaansa samalla kun shamaaneja pidetään nenetsiyhteisön ja tuonpuoleisen välisinä toimijoina, jotka vertautuvat eeppisten laulujen sankareihin.

Shamanistinen kerronta viittaa toistuvasti myyttisiin mielikuviin, mutta myös historiassa tunnettuihin aikoihin ja hetkiin, joissa myytti ja historia ovat sekoittuneet, olleet yhtä. Paikat, joissa myytti ja historia limittyvät, ovat menneisyyden ja nykyisyyden veitsenteriä. 


\section{Karina Lukin: Muisteltujen ja kerrottujen maisemien kerrokset}

\section{YHTEISÖ}

Tämän tutkimuksen aineisto on kerätty yhteisössä, joka on kipuillut neuvostoaikaisia ja neuvostoliiton hajoamiseen liittyviä muutoksia ja suhtautunut pessimistisesti omaan tulevaisuuteensa. Bugrino on ollut itselleni ja monille muille siellä vierailleille ulkopuolisille lohduton asutuskeskus, josta aukeaa näkymä kylmälle merelle ja tyhjälle tundralle.

Olennaista on ollut ymmärtää, että tyhjyys on illuusio. Kolgujev on saarelaisten arkisessa toiminnassa, muisteluissa ja kerronnassa elävä, tiheä suhteiden ja merkitysten verkosto. Saaren paikat eivät ole vain mäkiä, jokia, kotakyliä tai satamia eikä maisema suota, jokirotkoja ja tundraa. Niillä on historiansa, joka liittää paikat toisiin paikkoihin, Kolgujevin nenetseihin, heidän tuntemiinsa ihmisiin, saaren menneisyyden eri vaiheisiin, Kolgujevin ulkopuolisiin paikkoihin, joista nenetsit olivat tulleet ja joihin ulkopuoliset palasivat. Kerronta liittää paikat tuonpuoleiseen niin maan aliseen kuin yliseenkin. Erilaiset kerronnan ja muistelun tavat, lajit ja viittaukset niihin, luovat eritasoisia tapoja käsitteellistää saarta. Tutkimukseni on tämän päällekkäisten, limittäisten, verkottuneiden ja alati muuttuvien merkitysten kokonaisuuden kalpea kuva. Tämä kokonaisuus murtaa lohduttomuuden, joka oli yhtä suuri illuusio kuin tundran tyhjyyskin.

Lukin, Karina: Elämän ja entisyyden maisemat. Kolgujev nenetsien arjessa, muistelussa ja kerronnassa. Suomalaisen Kirjallisuuden Seuran Toimituksia 1339, Tiede. Helsinki: SKS.

\section{KirjallisuUs}

BASSO, KEITH H. 1996: Wisdom Sits in Places. Landscape and Language among the Western Apache. Albuquerque: University of New Mexico Press.

CASTRÉN, MATIAS ALEKSANTERI. 1870: Nordiska resor och forskningar I. M. $A$. Castrén's reseminnen från åren 1838-1844. Helsingfors: Finska Literatur-Sällskapet.

HALBWACS, MAURICE 1980 [1959]: The Collective Memory. New York, Cambridge, Hagerstown, Philadelphia, San Francisco, London, Mexico City, São Paulo, Sydney: Harper Colophon Books.

HOMITŠ, LJUDMILA VASILJEVNA1966: Nentsy. Istoriko-etnografiťseskije otšrerki. Leningrad: Nauka.

LEHTISALO, TOIVO 1924: Entwurf einer Mythologie der Jurak-Samojeden. SuomalaisUgrilaisen Seuran toimituksia 53. Helsinki: Suomalais-Ugrilainen Seura.

PEREPLETŠIKOV, VASILI VASILJEVITŠ 1917: Sever. Otšrkrki russkoj dejstvitelnosti. Moskva: Knigoizdatelstvo pisatelej v Moskve.

SAHLINS, MARSHALL 1985: Islands of History. Chicago and London: University of Chicago Press.

SIIKALA, ANNA-LEENA \& SIIKALA, JUKKA 2005: Return to Culture. Oral Tradition and Society in the Southern Cook Islands. FF Communications 287. Helsinki: Academia Scientiarum Fennica. 
Karina Lukin: Muisteltujen ja kerrottujen maisemien kerrokset

SIIKALA, ANNA-LEENA \& ULYASHEV, OLEG 2003: Landscape of Spirits: Holy Places and Changing Ritulas of the Northern Khanty. - Shaman 11(1 \& 2).

TONKIN, ELIZABETH 1992: Narrating Our Pasts. The Social Construction of Oral History. Cambridge: Cambridge University Press.

TREVOR-BATTYE AUBYN 2004 [1895]: Ice-Bound on Kolguev. A Chapter in the Exploration of Arctic Europe to which is Added a Record of the Natural History of the Island. [Uusintapainos.] Westminster: Archibald Constable and Company.

YOUNG, KATHARINE GALLOWAY 1987: Taleworlds and Storyrealms. The Phenomenology of Narrative. Hingham, Lancaster, Dordrecht: Kluwer Academic Publishers Group.

Filosofian tohtori Karina Lukin on tutkija Helsingin yliopiston folkloristiikan oppiaineessa. 